\title{
Good Practices for e-Business in the Travel Agencies
}

\author{
PhD candidate Hristina Santana \\ University of Economics - Varna, Varna, Bulgaria \\ hristina_santana@ue-varna.bg
}

\begin{abstract}
The digital transformation brought various effects to the travel agencies and their ability to cope with the contemporary online demand. The highspeeding OTA and meta-search engines confronted traditional businesses, which slowed innovation. The expansion of the pandemic of COVID-19 deepened the economic crisis and caused serious damage to the travel and tourism industry. It contributed great loss to the travel agents' sector and brought the necessity to discover new way of doing business. The purpose of the publication is to reveal some good practices for ebusiness to be enhanced by the travel agencies in order to keep their market position and financial liquidity.
\end{abstract}

Keywords: digitalization, innovation, good practices, e-business, travel agencies

JEL Code: Z320

DOI: https://doi.org/10.36997/IJUSV-ESS/2020.9.1.71

\section{Introduction}

The worldwide digitalization and the expansion of e-business brought various effects to the travel agents' sector. Some of the innovative organisations enhanced the idea of online functionalities implementation. Others considered them frustrating and unknown to the customer public. And yet, there is another group who consider e-business is the unwanted necessity. Three little words - Airbnb, Skyscanner, Uber have driven major disruption in the travel industry in the recent years. Travel agents witnessed some of the most profound changes in modern business - new digital platforms taught travellers how to book domestic and international travel. However, they didn't emerge for an overnight or in isolation. They simply reflect the trend of newly-empowered consumers getting what they want, when they want it.

Then, the travel industry came to an abrupt halt because of the COVID-19 pandemic. The world announced lockdown and travellers canceled or rescheduled trips. According to the World Tourism Organization, through May 2020, the pandemic has contributed a loss that is three times greater than the global economic crisis in 2009. That translates to a decline of 300 million tourists and $\$ 320$ billion lost in international tourism receipts. Yet, travel agents believe - when travel returns, it will come back strongly. There will always be need of vacation, excursions and business trips. New protocols were implemented in order to rearrange and restart travel and tourism industry. Distant, online procedures are recommended and enhanced. Non-personal communication and interactions are suggested, online sale and purchase is praised. In this situation travel managers believe customers will have greater necessity for professional consultation, though often provided in a digital way. They need to follow good e-business practices to cope better with "new normality". The object of the research are travel agencies striving for competitive advantages in the digital world. The purpose of the publication is to reveal some good practices for e-business to be enhanced by the organisations in order to keep their market position and financial liquidity.

\section{Online technology and travel distribution}

Travel agency business is engaged in providing the greatest number of travel sales towards the most appropriate customer society. As contemporary travellers are extremely active when it comes to Internet research of tourist information, they use multiple channels. They feel comfortable to review specialized travel web sites, to check on the social media and several travel blogs. Travellers also feel the necessity to share memories, experience and commentaries. As a result, the travel customer becomes more and more dependent on the online travel resources, abandoning traditional marketing messages. Digital platforms like TripAdvisor and HolidayCheck provoked to great extent the traditional tourism business. The information displayed in the web made the 
traditional travel agent more transparent. The customer, in turn, received entirely new distribution channel abundant of travel choices and booking options. The level of user's thrust varies according to the numerous e-platforms and social media. All marketing initiatives processed in the platforms resemble an up-to-date scope for the business to respond to customers' feedback and comments (either positive or negative ones). The messages sent, transfer quicker than standard ones, moreover - they attract greater attention. Travel organisations implementing online search engines prove to get better optimisation, market position and visibility while distributing travel information. It is of great advantage to provide direct links, leading the potential customer to the corporate travel website. The online channels provide numerous options for prepaid commercials, by registering number of user visits, clicks done, customer requests sent to the supplier.

Mobile technology innovation and its world-wide expansion enriched and transformed customer experience. Leading online travel agencies (OTA) and meta-search engines provide various mobile applications (Apps). By several clicks customers are enabled to plan trips and purchase travel and tourism services. No matter place and time zone, Internet speed and facilities, travel search and requests are being processed without having to leave personal home comfort. Special popularity among world travellers have mobile Apps for flight search like Skyscanner, Edreams, Opodo and the recent dominance of Google engine. Bulgarian customers have special affection towards eSky.bg, finding it easy to use and manage. The online travel guides and destination management organisations supply customers with actual and profound information about certain locations. It brings additional nuance to the business model of the travel organisations. Travel experience, the way travel companies interact and do business with their customers have changed (Wang et al, 2012).

Another transformation was caused by the distributing technologies that evolve day after day. The well-known and generally used by the travel agencies CRS/GDS are still present (Adeyfa et al, 2018) and keep improving functionalities, providing constant support and updates. System IT developers try to implement new modules on-time, creating innovative platforms and distribution channels (Cooper et al, 2018). OTA keep gaining power and market share due to the constantly improved Internet access, the developed 3G, 4G mobile networks and recent transition to the 5G technology (ITU, 2018). The variety in travel information supply allowed all travellers to make personal travel organisations and group certain products by individual interest. Meta-search engines provide massive amounts of online travel intermediaries offering different type of travel services, multiplying travel choice. The recent e-destinations contribute to the distributing technologies' development. Their platforms allow stakeholders to share knowledge and experience, intriguing facts about tourist destinations, thus increasing their market competitiveness and appeal. The expansion of electronically supplied products and services, even social media encouraged and facilitated sharing of tourist experience. This inevitably led to new business models implementation, based on equal, peer-to-peer interaction between users, which quickly transformed them into distinctively recognized ones. Airbnb and Couchsurfing are just an example of such special combination of mediation and distribution, actively contributed by the customer and the travel experience gained by them.

Studying consumer search and demand (Pearce, 2011) in a combination with the need of keeping travel agency's market position represents a great challenge. In this case, reviewing and following good world practices guaranties certain piece of success to the organisations. IT companies engaged in software solution provision, create Travel agency management modules enabling organisations to fluently process operational tasks and additional services. ${ }^{1}$ Thus, agencies have the opportunity to focus on strategic marketing goals, such as product popularisation and distribution. One of the main directions to follow is gaining clear communication and fluent interactions with customer and supplier of services. Vacation labs, for example, develop special

\footnotetext{
${ }^{1}$ Vacation Labs, for example, develop software systems for travel agency websites management, inventory, reservation systems, payment modules, mobile applications etc.
} 
software facilitating B2B (business-to-business) transactions between tour operator and travel intermediary. The software supplies customers with an easy access to the corporate web site of the intermediary and the leading supplier of services. Each sub-agent gets individual user account. The platform guarantees access to the entire informational data-base - available travel services, seats and accommodation, additional payment methods. Furthermore, tracking of customer digital footprints is performed, regardless the reservation is completed or left on hold. This gives opportunity to properly assess the electronic channel functionality; to compare its features to others; and based on actual reservations done, to navigate its future performance. To the tour operator, the software gives opportunities to easily customise preferences; to analyze rate levels in customer search; to make profiles of additional services inquired. The solution provides certain monitoring and control in information supply, as well as management in future bookings set by the individual customer.

It is of great advantage for the travel agents to have access to information hubs from anywhere in the world and from any electronic device - no matter PC, tablet or smartphone. For the purpose, e-Business has developed the "On the move technology" (Green, 2002), which actually gives control to its users. Service quality is relatively high, as the travel service distributor has full access to every component of the package (price, special conditions, additional services, discounts). The hub is reachable either from home, or the office, or out of town. The App provided minimizes high-speed Internet connection requirement as well as the need of office PC or laptop. The end-user or the B2B customer receives systemized information by e-mail or chat bot while actually both participants are no the move.

One of the easiest ways to highlight e-business in the travel agency daily activities is by assessing its website functionality. Its design, mode of information presentation, its content determines to great extent the usability of the respective site. Traffic, visualisations and site speed complete its general utility as for both the management and the end-users. Regarding travel agencies, the presence of visual media platforms has always been a factor to build-up good image and marketing performance. Contemporary customers rarely ask for paper travel brochures and catalogues, but prefer virtual tours in the chosen tourist destination. Worldwide, based on online search and surveys, according to TrekSoft and EMarketer, $82 \%$ of the tourist travel in 2018 has been purchased, using digital platforms. ${ }^{2}$ As a rule, the general affection of the society towards VR/AR, can be implemented in several e-business strategies (practices):

- Travel Agencies specialized in travel service sales aimed at younger customers (users) rely on messages, design and photos in the style of Internet influencers;

- Travel Agencies pursuing elder and retired customer groups, emphasize less on design, but create associations with peace and comfort, the tranquility aspects services offer.

Technology and e-business in the travel and tourism industry is an objective reality. Enhancing digital innovation and implementing electronic tools and functionality, brings various effects to the travel agencies. Customers often tend to transform preferences towards certain products and services depending on style, manner and form of display. VR/AR create immeasurable new dimensions in traditional travel. Digital platforms became permanent companion for the travel planner. That is why for the travel agent it is of crucial importance to evaluate a proper way and direction to develop business performance in order to keep loyal customers, gain new ones and remain unique in presentation and customer approach.

\section{Good practices for e-Business in the travel agency}

Some of the best and successful representatives of the worldwide practices are often described by their pleasant and appealing design, functionality, and the general ease in use. Such examples are the web-sites of: Context Travel; Holiday Pirates, Agoda, Airbnb, Rome2Rio, Get

\footnotetext{
${ }^{2}$ E-marketer.com - Global Digital Travel Sales 2018

https://www.trekksoft.com/en/resources/ebooks/travel-trends-report-2019
} 
your guide. The author of the publication reviews some of the well-known platforms to emphasize on the features of good practices in e-business sale and supply.

Agoda, originally based in Thailand and currently headquartered in Singapore, nowadays is part of the Booking Holding family and is the most often used OTA in the Asian continent. In its specifics, Agoda displays a non-crowded home page with several distinct tabs and menu. It is one of the reasons customers evaluate the site as very useful one. The brand is well-known and widely preferred, easy to deal with (user friendly). Everything you need is set on the home page: booking/reservation tool; change location tool; various links to hotel websites, flight offering platforms, airport transfer companies, and special offers. The hotel section of the website functions as an independent OTA and allows direct bookings. A distinctive feature of the web-site is its extremely proper place arrangement. By placing space-saving text links, the lack of clutter performs a clean big screen. As a bonus comes the option to customize the screen, even when the user is not in the system, which contributes to the personalized attitude feeling.

Airbnb is one of the biggest companies in the digital travel services providers' niche. It is of no wonder their large budget is directed towards constant functionality update and innovation. One of the best things about the platform underlies in its outstanding perceptiveness. Every single component of the web site is constantly reorganizing in the process of customer's search and according to their individual preference. In addition, the platform displays one of the smoothest transitions of views - from full screen (on a personal computer) to the level of a mobile device (tablet, smartphone). This is extremely useful as for the travel intermediary, browsing from the office location as well as for the end-customer using the mobile App. Airbnb users and customers highly praise the section "Experience". The company demonstrates eagerness in displaying and reviewing real customer experience. The accumulated data of user opinion and comments increases general customer appreciation and gains better levels of potential client interest.

Rome2Rio is a web-site which is not highly rated by it users as an extremely attractive in design and visual perspective digital travel portal. Its outlook is strikingly standard and far from outstanding. What makes it appreciated and preferred by customers is one of the most innovative and smart tools that can be found throughout the Internet - the so called transport search engine. By entering home address, airport of rail-way location, etc., the search engine displays immediate "door-to-door" travel option response - either by bus, plane, sailing boat, taxi or train. This exquisite tool allows the platform to gain best market position among the most stated digital travel agencies. Rome2Rio's approach helps them occupy the least competitive niche as even Google can't perform in a better way. In comparison, Google, are unable to provide the same functionality comfort though their Map App is highly rated and appreciated by customers.

Get your Guide is another example for a good e-business practice in travel agency organisations. It impresses with the amazing photos of tourist sites and destinations that sum up a kind of virtual travel tour. The display mode creates that special feeling for the user as if they are actually standing in front of the object of observation in the specific close proximity. The platform is a major example of the model and idea of how to make a real virtual tourist experience. Get your Guide maintain the assumption that "outstanding images actually sell travel trips" and this is why the company occupies leading places in the proper digital business positioning.

It is of special interest for the publication to review the Explore With locals web-site. The main activity of this online agency is related to the provision of a unique service in which the organisation collaborates with local population anywhere in the world. Relying on and actually using the local citizens' knowledge and experience, the company provides specialized travel tours to their customers. The potential problem of dealing with many languages and dialects in communication has also been successfully worked out. The web page is the perfect example of design, functionality level and systematic web-site odit while reviewing its separate categories location section, experience setting, gourmet tours in various cities, travel with children. The company approach is interconnected with the idea of strategic evaluation of the "most wanted" and 
preferred travel proposals and a subsequent focus on the most desired products and services.

Impressive for the study is the classification proposed by Tripsavvy, performing the best representatives among OTA in 2020. Considering the pandemic of COVID-19 it is very likely for the situation to change. However, OTAs still possess a great market portion of the online travel purchase and sale share. The classification is based on the principle of budget level, functionality tools, efficiency in services provided during the process of travel planning.

Booking.com is stated to be in general the best OTA as evaluated by customers. Founded in 1996, today the platform offers more than 29 mil. listings - hotels, hostels, vacation homes, luxury resorts. Customers have more choice on Booking.com than on any other OTA. The website performs well in terms of cost, typically returning lower-than-average prices for flights and hotels. The specially created helpdesk assists customers in terms of claims and complaints at certain accommodation spots. Booking.com takes care of every aspect of one's vacation, offering tours, activities, and airport taxis in addition to the standard services provided by most competitors. The interface is also easy to use, with an extensive list of filters to narrow the results down and find the best fit for the customer. The flights, car rental, and other tabs are just as intuitive.

Skyscanner is defined as the best budget travel web-site aggregator. Different OTAs often propose the cheapest prices for different dates and destinations. However, an aggregator site like Skyscanner uses a metasearch engine to compare prices from all OTAs and the airline, hotel, or car rental company thus competing best among similar sites. On test searches for specific hotel nights and flights, Skyscanner routinely delivered cheaper prices (sometimes by over \$100) than the major OTAs. Once the best rate is found, one click on the link redirects customer to a third party site to make travel booking. Tourists who book flights through Skyscanner are also eligible for further discounts on hotel bookings. They just need to make sure to have clicked on the Fly Stay Save icon to unlock them. For flexible passenger, the Search Everywhere button is available on the homepage. It suggests the cheapest flight deals for destinations both locally and across the world. For travellers who know where they want to go and have flexible dates, the search displays cheapest flights over a one-month period.

Expedia is the flagship for Expedia Group in the same way that Booking.com is the flagship for Booking Holdings. The two websites are aesthetically pretty similar and the basic premise is the same (although Expedia also offers cruises). However, Expedia is a particularly good option for those wanting to book a package vacation, i.e. to select and pay for flights, accommodation, and car rental in one search. The Hotels tab suggests to add a flight and/or car rental to customer's booking. Alternatively, the Bundle and Save tab allows them to book two or more of the following options: flights, hotel, and car rental. The OTA provides significant savings by booking these services at the same time. Making changes to a package booking can be complicated, however. Customers are advised to be sure with their plans before paying. If not perfectly sure the Deals tab is at disposal, grouping discount hotels and hotel/flight packages under themes like Family-Friendly Hotels or Extraordinary Luxury Hotels.

Lastminute.com is evaluated by the customers as the best OTA in Europe. It offers bookings anywhere in the world, but it's especially geared towards European travel and is one of the continent's top three travel companies. Hotels are booked directly and can be filtered according to budget, star rating, guest rating, board type, and more. The flight section uses a metasearch engine to find the cheapest price across associated OTAs and airlines and includes the ability to add multiple destinations - a major plus in Europe, where short travel distances make city-hopping a popular option. Lastminute.com also specializes in flight-and-hotel packages and all-inclusive vacation trips, often with great deals for last-minute travellers. Europe-specific travel services are also available, including Eurostar tickets (for those traveling in between the U.K. and mainland Europe), and West End theatre tickets. The company's Brexit Price Promise is another major benefit for visitors to the U.K. Regardless of what happens to the value of the pound as a result of Brexit, customers won't be charged any extra fees for existing bookings - even if a deposit is paid. 
Hotwire, as part of the Expedia Group, is a great fit for adventurous travellers who don't mind booking blind if it means receiving amazing discounts on last-minute deals. Hotels make their unsold rooms available to Hotwire at cheapest price available, allowing customers to buy them at a fraction of the normal price. However, users don't know the name of the property until booking is done. Essential information including star rating, guest rating and general location is revealed in advance, however, and some listings give a list of three possible hotels to book. Hotwire does offer conventional listings with the hotel name included, but prices for these hotels typically cost more than booking direct or with one of the bigger OTAs. Car rentals and flights are also available via a third-party comparison search that includes the company's Expedia Group siblings. Vacation packages are offered as well. Customers have the opportunity to bundle two or more options (e.g. flights, hotel, and/or car) for greater overall savings.

Most innovative among listed above OTAs is Kiwi.com. This independent flight-booking website works more like a metasearch engine with a difference. Unlike other aggregator sites, it allows customers to book each leg of a journey with the cheapest airline possible, even if they don't have a codeshare agreement. Such bookings may be risky, because the second airline is under no obligation to refund or rebook flight if the flight is missed (caused by a delay or cancelation on the first leg of the journey). However, Kiwi.com mitigate the risk with a unique guarantee that promises booking onto an alternative flight or refund the cost of unused ticket in case of a scheduling emergency. Other innovations that make this company unique are: on the homepage, an interactive map allows user to select departure city, then hover over international destinations to reveal the cheapest airfare for each route. The Nomad feature assists in finding the cheapest route for a multidestination trip and also offers pre-planned itineraries. Kiwi.com can arrange hotel bookings and car rentals through partnerships with Booking.com and Rentalcars.com

One of the most used by the Bulgarian customer platform is eSky.bg. Its direct connection to Amadeus GDS performs real-time flight information filtered by - Airway company, number of stops/stopovers, booking class etc. What is new and appreciated by customers is the Flight+Hotel combination (following the example of the German Tour Operators), the suggested city breaks, exotic travel options, beach vacations. Very innovative for the Bulgarian market is the eSky Wallet. This entirely new solution was created in response to the unprecedented necessity of the customers to refund unused services during the pandemic of COVID-19. Thanks to the wallet, passenger willing to refund unused flight or just a separate leg is eligible to receive amounts paid quickly as addition to the digital wallet. eSky Wallet allows travellers to raise funds for future trips using eSky up to 24 months from the moment of charge confirmation. The funds can be used to book airline tickets, as well as when organizing a trip by booking Flight + Hotel.

Innovations, by all means guarantee better long-term organizational goals' success. This is the case with corporate travel management and servicing. One of the best practices in corporate travel management is related to a special software solution implementation. Such an example is the TTS - travel and technology solution software. According to the Abacus Corporation survey on corporate travel from 2014, 2/3 of the worldwide corporate customers prefer to use the professional consultation provided by a travel agent. Corporate travellers depend on third party - travel agency to look after their business trips and company team-building programmes. Most of them consider planning an itinerary, flight reservation, hotel booking and accommodation, business facility supply at the destination point to be time consuming and heavy task to do. Moreover, $97 \%$ of the respondents (all of them business travellers) stated that they have been restricted by the companies to certain amounts of cost allowance during the trip. More often companies make flight booking in economy class than business even in the corporate niche. Another intriguing fact is that $73 \%$ of all business trips were planned and booked through Low cost Air companies. At one hand, fares are much lower than regular ones, on the other - Low cost airlines provide destinations not serviced by scheduled routes and regular flights or require transfers. There are numerous airports, serviced by Low cost companies which are actually located at close proximity or in the very heart of the 
destination city. Transfer services are easily supplied by the regular city transport or appointed shuttle service organisations. During the pandemic period, in a worldwide lockdown, the Low cost air companies supported some scheduled routes not only in Europe, but in the USA as well. This has had an extremely positive effect on the excessively restricted transport connections.

Regarding overnight stays, $47 \%$ of the questioned business travellers have stated that their hotel accommodation is far from the luxury category, but with secured Internet and business services. This requires a good knowledge of the accommodation spots, picking up the appropriate location, facilities and additional services. Saving company costs requires third party to look after business travel. In order to be able to offer quality service and data systematisation for corporate customers, large American and European travel agencies rely on reservation tools such as: Concur, Serko, TTS Corporate. ${ }^{3}$ What they have in common is that they provide reservation autonomy aimed at the corporate client. The listed software solutions monitor the cost levels of basic services, provide additional information to the accounting departments such as - car rental prices, mobile roaming and others. Approximately $37 \%$ of the world's TAs admit they trust such software solutions, which implement in the company business plan, together with installing some of the major GDS. ${ }^{4}$

An interesting and successful business practice turned out to be founding tourist organisations (such as Fair point, https://www.fair-point.com), serving customers from all over the world, specialized in MICE services. This specific service hub provides full package of travel and tourism assistance (air services, accommodation, transfers, passes for congress events and exhibitions). It is often located in a country with lower spending levels. The companies surround themselves with a team of IT specialists to write and support specific software solutions; experts from the tourism industry, specialised in travel service sales. Based on the outsourcing principle, the companies are registered in large business centres (Stuttgart, London, Washington), the offices are actually outsourced (for example in Bulgaria, India, Latin America). Leading principles are set in providing tour operator business services. Employees have good command of foreign languages and experience in travel package activity and organisation. Telephone and e-mail communication with customers is enhanced; own reservation and distribution channels with suppliers has been adopted. Good economies of scale and optimised booking process are registered. Each corporate client has an appointed personal account manager. The focus set is on the corporate customer, who has been supplied with specialised services and constant assistance. The companies achieve successful symbiosis between profitable business, successful and interactive partnership, loyal customers. The outsourced offices guarantee lower salary and social package costs to the company. At the same time, employees enjoy the imported working conditions and benefits from the main companies.

A consensus is yet hard to be reached regarding the concept of good practices in travel and tourism industry. Related to the travel agency business everything that can offer tourists the opportunity to co-create and develop their own creative potential and experience is considered a good practice. Contemporary travellers adopt fashion trends in daily routines as well as in travel. The pandemic of COVID-19 contributed to the customer affiliation to e-business tools and transformed it not only in a form of specific influence, but actual necessity.

\section{Results and discussions}

The good practices for e-business reviewed, give direction for the trends that should be followed by travel agencies aiming at digital transformation and transition. Today's world traveller is extremely digital. Mobile Apps, travel gadgets, digital booking tools and platforms seems to be their comfort zone. Satisfying their needs is invariably linked to adopting the best examples in the

\footnotetext{
${ }^{3}$ https://www.concur.com/

https://www.serko.com/

https://www.tts.com/

4 The traveller's Club, Marseille, for instance, incorporated similar corporate product.
} 
travel industry. The common features in the listed examples of good practices can be concluded in several main points that make them preferred by customers:

$\checkmark$ The principle of "Let's be Mobile". Mobile devices are gaining speed and greater share and therefore the web-pages design should be taken into account; the option of presenting the information on the App in the same way as on a personal computer. ${ }^{5}$

$\checkmark$ Large and outstanding images. Although good image quality makes them significantly harder to upload, properly compressed, the desired effect is achieved. Very often, in the form of an advertising strategy, images can be found at no extra charge on the web. However, personally taken photos are always praised by customers.

$\checkmark$ Integrated booking tools, devices, and reservation tabs. Custom booking tools are often too expensive, but this is one of the best ways to differentiate one company from the competition. The ability to build up personal company functionality creates a dominant position in the market niche. It is extremely important to create an easy to use web-site (user friendly), full of tips, effective category system. This attracts and stimulates customers to make more bookings.

$\checkmark$ Create a user experience of highest class. It is of paramount importance to understand exactly what the customer needs. The imposition of a website that fulfils the goals of the organisation is related to the proper acceptance by the user himself. This does not mean that the user must be in complete control. The best service provided is related to filling the specific gap in customer search. The process ensures efficiency in offering the right product aimed at the right customer.

$\checkmark$ Improved and modern payment methods, adding a digital wallet option. Customer security in refunds for non-provided services and guaranteeing the liquidity of the organisation at the same time (following the example of eSky).

The process of creating the proper communication and distribution channel requires a complete analysis of the market, the competition and consumer demand. Strategically, every travel agency, applying e-business practices in its activity consults and follows the experience of other market players. Usually the process of digital innovation takes into account competitive achievements in e-sales by approved wholesalers. The market positioning of travel agencies among huge competition depends on their financial capabilities and innovative approach. What makes them unique is the product itself, the form and manner in display.

\section{Conclusion}

The various forms of E-Business are offering major opportunities for all travel and tourism industry members. No matter size and attraction of destination, number of travel suppliers and gained market share, whether large or small tourist organisation, every stakeholder aims to improve their business. One option is to perform a better image and digital performance, to remodel their business in new and more cost-effective ways. Today, more than ever, travel agencies have faced the technological changes that brought major digital transformation to the society, the customers and the organisations themselves. In order to be able to handle the e-business impacts, to actually keep market position, organisations are obliged to apply principles of cooperation, collaboration and resource sharing. Following good and proved to be successful practices contributes to the strategic mission of any institution - stay strong among competition, increase market share and gain repeating customers.

\section{References}

1. Adeyefa, A. E., Olasoju, O. O., Omemu, A. M., Adedipe, A., \& Oladosu, O. A. (2018) Perception of Travel Agents Towards Amadeus And Galileo Global Distribution System. Canadian Social Science, http://www.cscanada.net/index.php/css/article/view/10633 DOI:

\footnotetext{
5 Typical examples are Twitter andYouTube. No matter browser used, set on the desktop or the mobile device, visualization and quality in performance stays equal.
} 
http://dx.doi.org/10.3968/10633

2. Cooper, Ch. S. Volo, W. Gartner, N. Scott (2018) The SAGE Handbook, SAGE

3. Green, N. (2002) On the Move: Technology, Mobility, and the Mediation of Social Time and Space, The Information Society 18(4):281-292 DOI: 10.1080/01972240290075129

4. Pearce, Ph., Tourist Behaviour and the Contemporary World (2011), CVP, Bristol, UK

5. Wang,X., Y. Chunling, J.Wei, (2012) Social Media Peer Communication and Impacts on Purchase Intentions: A Consumer Socialization Framework, Journal of Interactive Marketing 26(4):198-208, DOI: 10.1016/j.intmar.2011.11.004

6. Internet references:

https://edition.cnn.com/travel/article/travel-influencers/index.html

https://www.weforum.org/agenda/2020/05/travel-safety-europe-coronavirus/

E-marketer.com - Global Digital Travel Sales 2018, accessed on 20/06/2020

https://www.trekksoft.com/en/resources/ebooks/travel-trends-report-2019, accessed on 23/08/2020.

https://forwardkeys.com/ accessed on 04/05/2020

https://www.concur.com/_accessed on 06/05/2020

https://www.serko.com/ accessed on /05/2020

esky.com accessed on 06/05/2020

https://www.thesavvyglobetrotter.com/ accessed on 29/09/2020 